\title{
Full-scale model study on variations of soil stress in geosynthetic-reinforced pile-supported track bed with water level change and cyclic loading
}

\author{
Han-Lin Wang, Ren-Peng Chen, Wei Cheng, Shuai Qi, and Yu-Jun Cui
}

\begin{abstract}
This study presents a full-scale model investigation on variations of soil stress in a geosynthetic-reinforced pilesupported track bed at various water levels and loading cycles, with four testing procedures: water level rising, cyclic loading at high water level, water level lowering, and cyclic loading at low water level. The soil arching effect was revealed, characterized by higher stress above the pile cap. With the water level rising and loading cycles increasing at high water level, this effect becomes more pronounced, until a peak value of dynamic stress concentration ratio is reached. The stable state of soil arching is obtained earlier near the crown of soil arching, but this arching effect develops more significantly at the foot of soil arching. With the water level lowering and loading at low water level, the soil arching effect remains steady, with slightly changed dynamic stresses in the track bed. The geogrid shows a significant impact on the load transfer mechanism for the quasi-static stress: the quasi-static pile-cap stress presents higher values below the geogrid, whereas the opposite trend is observed for the water-bag (subsoil) area. Nevertheless, this mechanism is not obvious with respect to the dynamic stress, with the values showing no distinct difference above and below the geogrid.
\end{abstract}

Key words: geosynthetic-reinforced pile-supported track bed, water level, cyclic loading, soil arching, geogrid reinforcement.

Résumé : Cette étude présente une étude de modèle grandeur nature sur les variations des contraintes du sol dans des plates-formes sur pieux renforcées par géosynthétique à différents niveaux d'eau et cycles de chargement, avec quatre procédures d'essai : élévation du niveau d'eau, chargement cyclique à niveau d'eau élevé, abaissement du niveau d'eau et chargement cyclique à niveau d'eau bas. L'effet de voûte du sol a été révélé, caractérisé par une contrainte plus élevée au-dessus du chapeau de pieu. Lorsque le niveau d'eau augmente et que les cycles de chargement augmentent à niveau d'eau élevée, cet effet devient plus prononcé, jusqu'à ce qu'une valeur maximale du rapport de concentration des contraintes dynamiques soit atteinte. L'état stable des voûtes du sol est obtenu plus tôt près du sommet de voûte du sol, mais cet effet de voûte se développe de manière plus significative au pied de voûte du sol. Avec l'abaissement et le chargement du niveau d'eau à un niveau d'eau bas, l'effet de voûte du sol reste stable, avec des contraintes dynamiques légèrement modifiées dans la plate-forme de la voie. La géogrille montre un impact significatif sur le mécanisme de transfert de charge pour la contrainte quasi-statique : la contrainte quasi statique de chapeau de pieu présente des valeurs plus élevées sous la géogrille, tandis que la tendance inverse est observée pour la zone du sous-sol. Néanmoins, ce mécanisme n'est pas évident pour la contrainte dynamique, les valeurs ne montrant aucune différence nette au-dessus et en dessous de la géogrille. [Traduit par la Rédaction]

Mots-clés : plate-forme sur pieux renforcée par géosynthétique, niveau d'eau, chargement cyclique, effet de voûte du sol, géogrille de renfort.

\section{Introduction}

Compared to the track bed with subsoil improved by conventional methods, the geosynthetic-reinforced pile-supported (GRPS) track bed presents smaller accumulative settlement and is thus increasingly used in the new high-speed railway lines in China (Zhou et al. 2012; Chen et al. 2014, 2016b; Wang et al. 2018a). The foundation of the pile-supported track bed is commonly improved by an array of piles with caps on them. The additional improvement such as the application of a geogrid reinforcement layer is also considered in some embankments (Han and Gabr 2002; Heitz et al. 2008; van Eekelen et al. 2012a, 2012b, 2013; Zhuang and Wang 2015; Chen et al. 2016b; Wang et al. 2018a).
Because of the stiffness difference between the piles and the surrounding soils, larger settlement tends to develop for the subgrade fill above the surrounding soft soil, which induces the well-known soil arching effect, with more pressure transferring onto the pile caps (Terzaghi 1943; Hewlett and Randolph 1988; Low et al. 1994; Han and Gabr 2002; Chen et al. 2008; Heitz et al. 2008; van Eekelen et al. 2012a, 2012b, 2013; Chen et al. 2014, 2016b; Zhao et al. 2016, 2017; Wang et al. 2018a). After the development of soil arching, the evolution of soil stress inside the track bed may present different patterns. Thereby, it appears essential to assess the variations of the soil stress for the safety and serviceability of railway track beds (Chen et al. 2016a; Wang et al. 2017, 2018a, 2018b, 2018c).

Received 29 November 2017. Accepted 16 April 2018.

H.-L. Wang and R.-P. Chen. MOE Key Laboratory of Building Safety and Energy Efficiency (Hunan University), Changsha, China; College of Civil Engineering, Hunan University, Changsha, China.

W. Cheng and S. Qi. Department of Civil Engineering, Zhejiang University, Hangzhou, China.

Y.-J. Cui.* Laboratoire Navier/CERMES, Ecole des Ponts ParisTech (ENPC), Champs-sur-Marne, France.

Corresponding author: Ren-Peng Chen (email: chenrp@hnu.edu.cn).

${ }^{*}$ Y.-J. Cui currently serves as an Associate Editor; peer review and editorial decisions regarding this manuscript were handled by E.M. Palmeira.

Copyright remains with the author(s) or their institution(s). Permission for reuse (free in most cases) can be obtained from RightsLink. 
Fig. 1. Schematic view of full-scale testing model: $(a)$ profile view; (b) plan view. [Color online.]
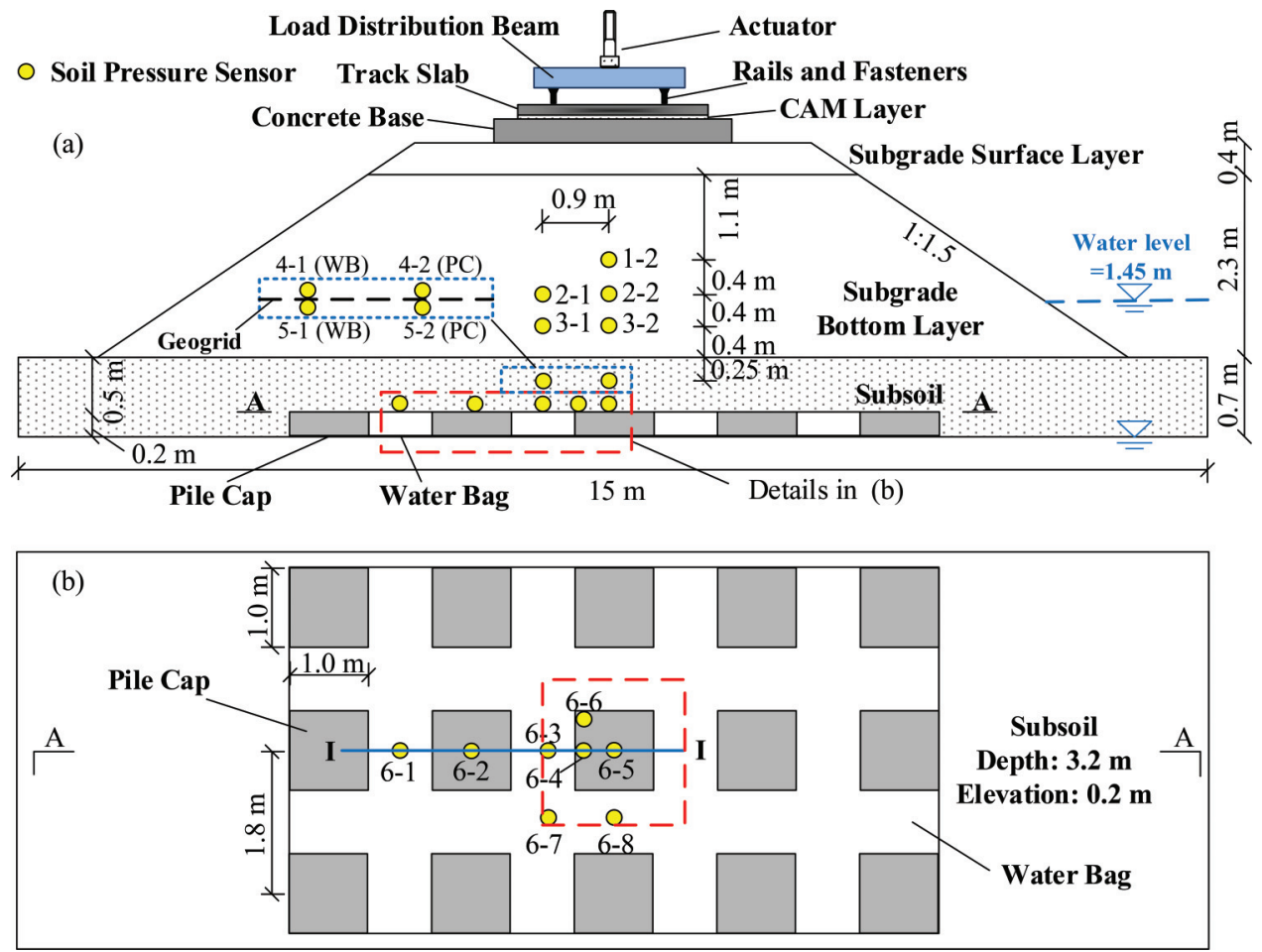

To date, the distribution of soil stress in the embankment have been investigated in terms of the soil arching effect in several studies by analytical and experimental methods. Terzaghi (1943) firstly used the classic trap-door test to evaluate the soil stress on the trap door (subsoil). Hewlett and Randolph (1988) conducted small-scale model tests on dry and moist sand foundation with wood piles and a semi-spherical model for the soil arching effect was proposed. Low et al. (1994) found a theoretical solution for the soil arching in the soft-soil embankment supported by piles, showing a good agreement with the model test without geotextiles. Han and Gabr (2002) studied the effects of geosynthetic stiffness and pile modulus on soil arching in the GRPS embankment through numerical analysis, verifying the impact of the geosynthetic on reducing the total and differential settlement. Chen et al. (2008) indicated that the soil arching is also strongly affected by embankment height, reinforcement strength, pile cap width, and pile spacing. van Eekelen et al. (2013) proposed a concentric arching model to estimate the soil stresses distributed on the pile, geogrid, and subsoil separately, from a series of model tests (van Eekelen et al. 2012a, 2012b). Based on the model of Hewlett and Randolph (1988), Zhuang et al. (2014) presented a simplified model to assess the mechanical behaviors of the embankment supported by reinforcement and piles. Using a full-scale model of railway track bed, Chen et al. (2016b) identified the evolution of soil arching caused by the pile-soil differential settlement. However, the above-mentioned studies all concentrate on the stress distribution of the embankment under static or self-weight loading. For the railway track bed, the common traffic loading is cyclic or dynamic that is induced by the passing trains. Thereby, a good knowledge on the mechanism related to the dynamic response in the track-bed soil under cyclic loading remains crucial (Heitz et al. 2008; Gomes Correia and Cunha 2014; Jenck et al. 2014; Han et al. 2015; Kang et al. 2016; Wang et al. 2017, 2018c).

Using a 1:3 scale model of a GRPS embankment, Heitz et al. (2008) identified a different load transfer mechanism under sinusoidal cyclic loading, with higher strains in the geogrid, soil arching reduction, larger stress, and larger settlement. Based on a small-scale trap-door model test, Han et al. (2015) investigated the stress distribution and stability of an embankment of various heights with soil arching effect under cyclic loading; a minimum height of embankment was reported to ensure the stability of the model. Nevertheless, the model size of the previous studies presents significant limitations to evaluate the stress variations in the real pile-supported track bed. Furthermore, extreme climate conditions especially the intense precipitations are becoming more frequent worldwide, leading to the reduction of soil strength and increase in the water level (WL) (Jiang et al. 2015, 2016; Wang et al. 2015, 2018a; Chen et al. 2018). As a result, some water-related engineering problems induced by high WLs were identified in the last decades (Transportation Safety Board of Canada 1998; Lindgren et al. 2009; Chinanews 2012; Wang et al. 2018a). However, the previous studies only deal with the stress variations under cyclic loading at constant moisture contents or at unsaturated state. To the author's knowledge, the issue about the coupled effects of varying WLs and loading cycles on the variations of soil stress in a GRPS track bed has not been addressed yet.

In this study, using a full-scale GRPS track-bed model, the variations of soil stress were investigated at various WLs and loading cycles. The WL herein refers to the free water table estimated from the bottom of the model. The soil arching effect was firstly developed by the pile-soil differential settlement, simulated by the drainage of the water bags surrounding the pile caps at the bottom of the model. Then, after 1200000 loading cycles at the train speed of $324 \mathrm{~km} / \mathrm{h}$ at unsaturated state, four testing procedures were applied: WL rising, loading at high WL, WL lowering, and loading at low $\mathrm{WL}$. The results of soil stress were discussed in three parts: soil stress distribution with depth, soil stress variation along the geogrid, and soil stress variation on the top of piled system. The evolution of soil arching and the load transfer mechanism were analyzed with changing WLs and loading cycles.

\section{Materials and methods}

Setup of full-scale model

The schematic view of the full-scale physical model of the GRPS railway track bed is shown in Fig. 1, constructed in a steel chamber 
Fig. 2. Grain-size distribution curves of materials. [Color online.]

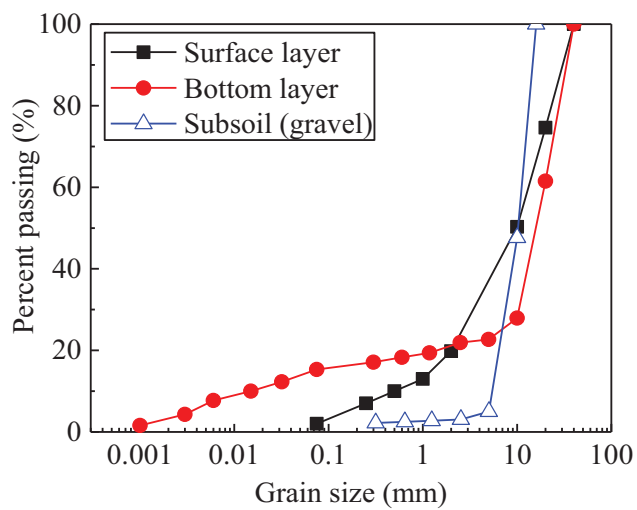

with dimensions of $15 \mathrm{~m} \times 5.5 \mathrm{~m} \times 4 \mathrm{~m}$ (height). This model was set up in accordance with the Chinese design code TB10621-2009 (The Ministry of Railways of the People's Republic of China 2009), consisting of the superstructure and substructure. In the superstructure, to simulate the train moving loads, eight separated $300 \mathrm{~mm}$ length CHN-60 type rails were set along the longitudinal direction of the model on each side. Each segmented rail was fixed onto the surface of the CRTS-I type track slab $(4.96 \mathrm{~m} \times 2.4 \mathrm{~m} \times 0.19 \mathrm{~m})$, with the application of the WJ-7 type fastener. Below the track slab, a cement asphalt mortar (CAM) layer and a C40 concrete base $(5 \mathrm{~m} \times$ $3 \mathrm{~m} \times 0.3 \mathrm{~m}$ ) were placed. At each side of the concrete base, five holes (50 $\mathrm{mm}$ diameter, $200 \mathrm{~mm}$ depth) were prepared along the longitudinal direction for the purpose of water injection.

For the substructure, three layers were constructed including the surface layer of subgrade ( $0.4 \mathrm{~m}$ height), the bottom layer of subgrade ( $2.3 \mathrm{~m}$ height), and the subsoil ( $0.7 \mathrm{~m}$ height) from top to bottom (Fig. 1a). The slopes of the subgrade were set as 1:1.5 (height: width). The horizontal level $0 \mathrm{~m}$ was considered as the bottom line of the model. In the subsoil, a geogrid cushion was installed at the elevation of $0.45 \mathrm{~m}$, with the ultimate tensile strength of $130.6 \mathrm{kN} / \mathrm{m}$, ultimate strain (at tensile strength) of $8.22 \%$, and tensile stiffness (at strain of $2 \%$ ) of $2459.5 \mathrm{kN} / \mathrm{m}$ (see more detailed parameters in Wang et al. 2019). To protect the geogrid cushion, a sand layer ( $0.2 \mathrm{~m}$ thickness) was applied to wrap this reinforced system. At the bottom of the subsoil, 15 C40 concrete slabs $(1 \mathrm{~m} \times 1 \mathrm{~m} \times 0.2 \mathrm{~m})$ were arranged with the centerto-center spacing of $1.8 \mathrm{~m}$ to simulate the pile caps in the pilesupported foundation (Fig. 1b). Between these pile caps, several water bags made of polyvinyl chloride were set, connected to a water-supply system. Several wood boards with the unified thickness of $0.01 \mathrm{~m}$ were used to protect the water bags from being punctured by the coarse grains. During the construction of the model, the water bags were injected with water to the full state, in which case they could share the same height (height including the wood boards) as the pile caps. After the model was built, the drainage process of the water bags was followed in steps, to simulate the pile-soil differential settlement in the pile-supported foundation (Wang et al. 2018a).

\section{Testing materials}

Figure 2 shows the grain-size distribution curves of the substructure soils. Table 1 lists the specific properties of each soil. According to ASTM (2011) standard D2487-11, the material of surface layer can be classified as well-graded gravel (GW). The maximum grain size of the subgrade soils (surface layer and bottom layer) is $40 \mathrm{~mm}$, while the material of the bottom layer has a higher fines (particle size $<0.075 \mathrm{~mm}$ ) content as $15.4 \%$. By measuring the Atterberg limits of the fines in the bottom layer, the liquid limit and plasticity index were determined as $24 \%$ and $13 \%$, respectively. The bottom layer is thus classified as clayey gravel
Table 1. Soil properties.

\begin{tabular}{llclll}
\hline Soil & $\gamma\left(\mathrm{kN} / \mathrm{m}^{3}\right)$ & $c(\mathrm{kPa})$ & $\varphi\left(^{\circ}\right)$ & $K$ & $K_{30}(\mathrm{MPa} / \mathrm{m})$ \\
\hline Surface layer & 19.6 & 1.2 & 50.3 & 0.97 & $236-273$ \\
Bottom layer & 22.7 & 16.3 & 43.6 & 0.97 & $158-197$ \\
Subsoil (gravel) & 18.4 & 0 & 40 & - & - \\
\hline
\end{tabular}

Note: $\gamma$, unit weight of soil; $c$, cohesion; $\varphi$, internal friction angle; $K$, compaction coefficient; $K_{30}$, stiffness at displacement of $1.25 \mathrm{~mm}$ through static plate loading test.

(GC, see ASTM (2011) standard D2487-11). For the subsoil, it is categorized as poorly graded gravel (GP). Note that these three trackbed soils were all extracted from the field sites of railway construction in Yuhang, Hangzhou, China. Before using these materials, the soil properties and classifications were examined, showing a good agreement with the stipulations of the standard TB10621-2009 (The Ministry of Railways of the People's Republic of China 2009).

During the construction of the model, each soil was compacted to reach a high-density state with a moisture content of $4 \%$ to $7 \%$. The thickness of each compacted layer was $200 \mathrm{~mm}$. Note that the moisture contents were controlled as $4 \%-7 \%$ to correspond to the optimum water content of the bottom layer (5.9\%). The stiffness parameters were measured by static plate loading tests for each subgrade layer, to ensure the compaction quality. The testing results are listed in Table 1, showing a good agreement with TB10621-2009 (The Ministry of Railways of the People's Republic of China 2009) (Wang et al. 2018a).

\section{Instrumentation and testing procedures}

To measure the soil stress, several soil pressure sensors (produced by Geokon Technology Co., Beijing, China) were embedded in the substructure as shown in Fig. 1. The diameter of the sensor is $230 \mathrm{~mm}$ and the measuring range is $0-350 \mathrm{kPa}$. During the measuring process, these sensors were connected to a data acquisition apparatus namely MOI sm130 (Micron Optics Inc., Atlanta, USA) and the testing frequency was $100 \mathrm{~Hz}$. To protect the sensors and to ensure the homogeneous soil stress transmission onto the sensors, a sand layer with $10 \mathrm{~mm}$ thickness was placed on the top and bottom sides of each sensor.

The loading system consists of eight servo-hydraulic actuators, eight load distribution beams, and a reaction beam (Fig. 1). Each load distribution beam was fixed to one actuator and this beam could be lowered to be in contact with each pair of rails using the controlling system. Then, each actuator generated the cyclic load with a peak force of $140 \mathrm{kN}$ (the axle load of the CRH3 type moving train carriage) and a pre-determined loading frequency related to the train speed (see more details in Wang et al. 2018a). An M-type wave could be developed, simulating the configuration of the train carriage. Finally, based on the sequential loading method, the train moving loads as high as $360 \mathrm{~km} / \mathrm{h}$ could be simulated. Note that the sequential loading method is characterized by the phase lag of the applied loads between the adjacent actuators of the model. As the distance between the adjacent actuators is fixed as $0.625 \mathrm{~m}$ in the model, the phase difference can thus be determined as $9^{\circ}$ by considering the loading wavelength as the length of one CRH3 type carriage ( $25 \mathrm{~m}$, see Wang et al. 2018a).

To simulate the soil arching effect in the pile-supported track bed, the water in the water bags was drained out by step to control the settlement of the soft soil between the pile caps prior to the present study (Wang et al. 2018a). With the pile-soil differential settlement, soil arching was thus developed, characterized by a lower soil stress above the water bags and a higher pressure above the pile caps in the arching area. This effect became stable after the water bags were fully drained, leading to the height of soil arching as $1.3 \mathrm{~m}$ (estimated from the top of the pile caps, see Wang et al. 2018a). In other words, the elevation of the top of the soil arching was $1.5 \mathrm{~m}$ from the bottom of the model, including the 
Fig. 3. Water level variations. [Color online.]

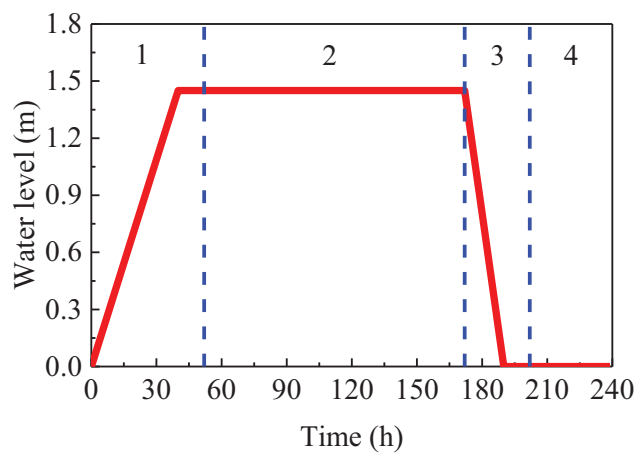

thickness of the pile cap. Then, to approach the in situ soil state, cyclic loading at the train speed of $324 \mathrm{~km} / \mathrm{h}$ was applied on the unsaturated model for 1200000 cycles.

Four testing procedures were considered in this study. Firstly, the soil stresses were measured by the pre-embedded sensors at a train speed of $360 \mathrm{~km} / \mathrm{h}$ at initial unsaturated state (loading cycles less than 50 ). Then, in procedure 1 , the WL was raised from 0 to $1.45 \mathrm{~m}$ by injecting water through the pre-penetrated holes at each side of the concrete base. Figure 3 shows the variations of the WL during the test. Note that the high WL $1.45 \mathrm{~m}$ was selected according to the height of soil arching. For moisture homogenization and stability of the stress redistribution, the WL was kept still for $12 \mathrm{~h}$ after having been increased to $1.45 \mathrm{~m}$. In procedure 2 , the train moving loads representing different speeds were applied with constant high $\mathrm{WL}$. The detailed loading process is listed in Table 2. Loading ended when the settlement of the whole track bed became steady. In procedure 3 , the WL was lowered from 1.45 back to $0 \mathrm{~m}$, by using the drainage system at the bottom of the model. Twelve hours were also applied for moisture homogenization and stability of stress redistribution before the next procedure. Finally, in procedure 4, train moving loads at the speed of $360 \mathrm{~km} / \mathrm{h}$ were applied till the stabilization of the settlement of the whole track bed. At the end of process 1 and processes 4-12 (Table 2), cyclic loading at the train speed of $360 \mathrm{~km} / \mathrm{h}$ with less than 50 cycles was applied again to measure the soil stresses. Note that as the extra loading cycles to determine the dynamic stresses in the track bed (including the initial cyclic loading applied before procedure 1, with less than 50 cycles) are much smaller than those for the long-term cyclic loading in this study (1 020000 cycles), these extra cycles are not considered in the testing program (Table 2).

\section{Results and discussions}

Figures $4 a$ and $4 b$ depict the typical signals of measured soil stress for sensor 1-2 (Fig. 1) at initial unsaturated state, without applied train moving load and at the simulated train speed of $360 \mathrm{~km} / \mathrm{h}$, respectively. Under the self-weight of the track bed (without applied train moving load), the static soil stress $\sigma_{\mathrm{s}}$ stays relatively constant at about $61 \mathrm{kPa}$ (Fig. 4a). By contrast, under the train moving loads, regular M-type signals are obtained, with each M-type loading cycle corresponding to two bogies between the adjacent carriages and each peak value corresponding to one bogie (Fig. $4 b$ ). For each M-type loading cycle, the trough (minimum) value is defined as the quasi-static soil stress $\sigma_{\mathrm{q}-\mathrm{s}}$ (Fig. $4 b$ ), which refers to the stress at the train speed of $0 \mathrm{~km} / \mathrm{h}$ (Bian et al. 2014). In other words, the quasi-static stress indicates the soil stress when no train moving load is applied. Indeed, for the same sensor, the quasi-static stress shows similar values as the static stress (both around $61 \mathrm{kPa}$, see Fig. 4), validating that the quasi-static stress during cyclic loading can well represent the static stress. In this study, the dynamic soil stress $\sigma_{\mathrm{d}}$ is defined as the stress amplitude during cyclic loading (Fig. $4 b$ )
Table 2. Loading procedures.

\begin{tabular}{lcllc}
\hline $\begin{array}{l}\text { Testing } \\
\text { procedure }\end{array}$ & Process & $v(\mathrm{~km} / \mathrm{h})$ & $N_{1}(\times 1000)$ & $N(\times 1000)$ \\
\hline 1 & 1 & - & - & 0 \\
2 & 2 & 108 & 60 & 60 \\
& 3 & 216 & 60 & 120 \\
& 4 & 360 & 150 & 270 \\
& 5 & 360 & 100 & 370 \\
& 6 & 360 & 100 & 470 \\
& 7 & 360 & 100 & 570 \\
& 8 & 360 & 100 & 670 \\
3 & 9 & 360 & 150 & 820 \\
4 & 10 & - & - & 820 \\
& 11 & 360 & 100 & 920 \\
& 12 & 360 & 100 & 1020 \\
\hline
\end{tabular}

Note: $v$, simulated train speed; $N_{1}$, loading cycle for each process; $N$, accumulative loading cycle.

$$
\sigma_{\mathrm{d}}=\sigma_{\max }-\sigma_{\mathrm{q}-\mathrm{s}}
$$

where $\sigma_{\max }$ is the crest (maximum) value. This dynamic stress (stress amplitude) is induced by the train moving load. Thus, the self-weight of the track bed is not included in the dynamic stress, but in the static or quasi-static soil stress. Note that as less than 50 loading cycles were applied to estimate the soil stress variation after the specific loading processes shown in Table 2, the recorded loading signals remained unchanged for the same sensor during the small number of loading cycles. Hence, in the following analysis, the quasi-static stress $\sigma_{\mathrm{q}-\mathrm{s}}$ and dynamic stress $\sigma_{\mathrm{d}}$ are determined as the minimum value and stress amplitude of the steady recorded loading cycles of each sensor, respectively, as illustrated in Fig. $4 b$.

As reported by Chen et al. (2014) and Han et al. (2015), the distributions of dynamic stress are not uniform above the pile cap and subsoil in the soil arching area. Hence, in consideration of the uneven stress distribution in the track bed after the development of the soil arching effect, a parameter, namely dynamic stress concentration ratio, $n$ is defined to interpret the degree of soil arching at a given elevation as

$$
n=\frac{\sigma_{\mathrm{d}-\mathrm{PC}}}{\sigma_{\mathrm{d}-\mathrm{WB}}}
$$

where $\sigma_{\mathrm{d}-\mathrm{PC}}$ and $\sigma_{\mathrm{d}-\mathrm{wB}}$ are the dynamic soil stresses above the pile caps and water bags, respectively. From the definition, it is indicated that a higher degree of soil arching can be represented by a higher value of $n$.

The analyses of the testing results are illustrated in three parts: the dynamic soil stress distribution with depth above the geogrid (including sensors $1-\mathrm{X}, 2-\mathrm{X}, 3-\mathrm{X}$, and $4-\mathrm{X}$ ); the soil stress variation along the geogrid (including sensors 4-X and 5-X); the dynamic soil stress distribution on the top of piled system (including sensors 6 -X). The locations of the sensors can be seen in Fig. 1.

\section{Soil stress with depth (above geogrid)}

Figure 5 plots the variations of the dynamic soil stress with depth after typical processes (initial state, end of procedures 1, 2, 3 , and 4). In this study, the dynamic soil stress refers to the measured total stress amplitude (Fig. 4b). In Fig. 5, the legend "WL0-0 cycle" indicates the measurement conducted at the WL of $0 \mathrm{~m}$ after 0 accumulative loading cycle $(N)$. This legend is also used in the following figures. In addition, the solid points represent the measured values above the pile caps and the hollow points for the water bags.

From Fig. $5 a$, it can be observed that at the initial unsaturated state, the distribution of the dynamic soil stress below the height 
Fig. 4. Typical measured soil stress for sensor 1-2 at initial unsaturated state: $(a)$ without applied train moving load; (b) at simulated train speed of $360 \mathrm{~km} / \mathrm{h}$. [Color online.]

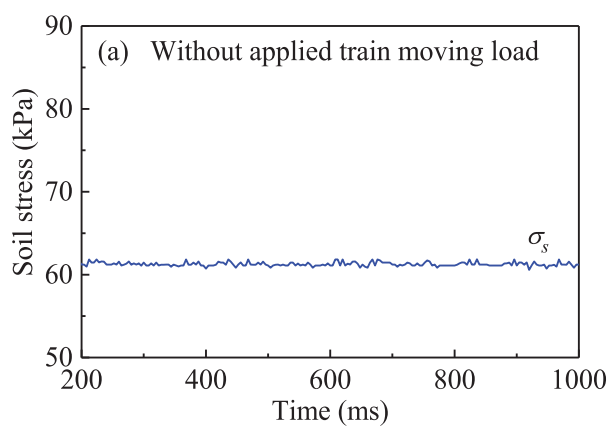

Fig. 5. Variations of dynamic soil stress with depth after typical processes. Note: solid and hollow points for dynamic stresses above pile cap and water bag, respectively. [Color online.]
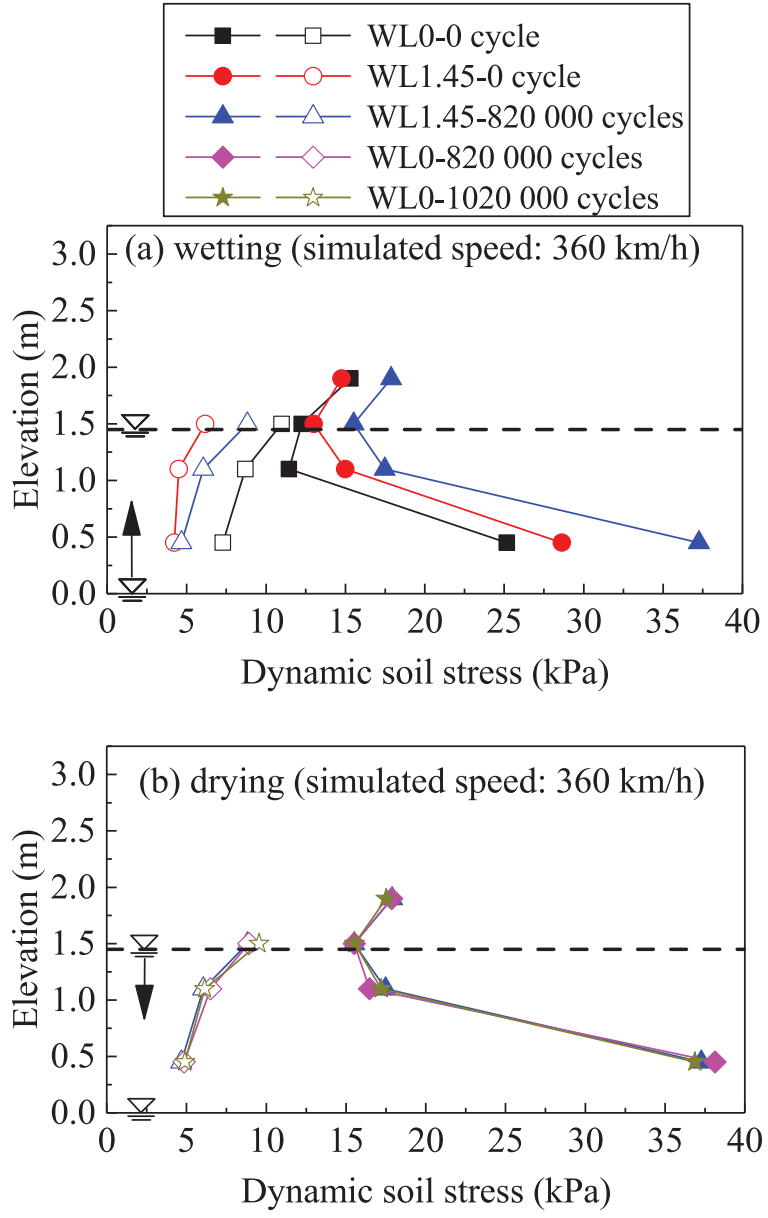

of soil arching (elevation $<1.5 \mathrm{~m}$ ) presents distinct arching effect, with the $\sigma_{\mathrm{d}}$ values increasing with the increase of depth above the pile caps and the $\sigma_{\mathrm{d}}$ values showing opposite variation trend above the water bags. As the WL increases to $1.45 \mathrm{~m}$ before longterm loading, the $\sigma_{\mathrm{d}-\mathrm{PC}}$ values above the soil arching stay the same as the initial state, while the $\sigma_{\mathrm{d}-\mathrm{PC}}$ values below the soil arching increase by about $3 \mathrm{kPa}$ at a given elevation. By contrast, the dynamic soil stresses above the water bags decrease at a given elevation compared to the initial state. This is probably due to the fact that after the drainage of the water bags, larger settlement occurred above the water bags, leading to a less compacted state of soils in this area compared to the soils above the pile caps. As

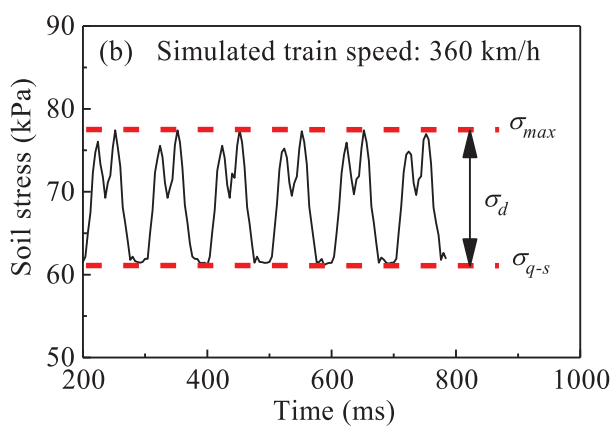

the WL increased, the effective stress of the soil solid decreased. Under the load from the overlying soil and superstructure, part of the skeleton of the soil with less compacted state above the water bag failed to support the whole structure, inducing a relative settlement above the water bag in comparison with that above the pile cap. Thus, the shear stress at the interface of soils above the water bag and pile cap increased. As a result, the soil arching effect was strengthened, with part of the dynamic soil stress above the water bag transferred to that above the pile cap. After 820000 loading cycles at high WL, the dynamic stresses above the pile caps and water bags both increased because the soils in the substructure were more compacted after the long-term cyclic loading.

With the WL lowering and loading at low WL $(0 \mathrm{~m})$, it can be seen from Fig. $5 b$ that the dynamic soil stresses above the pile caps and water bags both changed slightly. This suggests that after 820000 loading cycles at high WL, the full-scale model including the soil arching entered a relatively stable state. With the WL lowering and loading at low WL, the stable soil arching remains at the steady state. Hence, the dynamic stresses are slightly influenced by the WL or cyclic loading in these two testing procedures. This observation is strongly supported by the negligible variation of the differential settlement between the water bag and the pile cap during the testing procedures of $\mathrm{WL}$ lowering and loading at low WL, as reported by Wang et al. (2018a).

To have a better understanding of the evolution of the soil arching, the values of dynamic stress concentration ratio $n$ at three elevations (sensors 2-X, 3-X, and 4-X) are plotted with changing WLs and loading cycles, as shown in Fig. 6 . The initial state at the WL equal to $0 \mathrm{~m}$ before long-term cyclic loading is presented in this figure, shown as "WL0-0 cycle". Cycles from N=0 to 820000 refer to the process of cyclic loading at high WL $(1.45 \mathrm{~m})$ and cycles from $N=820000$ to 1020000 represent the case for low WL $(0 \mathrm{~m})$ loading (see more details in Table 2). The results indicate that, at a given elevation, the $n$ value increases with the rising of WL and continues to increase as the loading cycle increases at high $\mathrm{WL}$, until reaching the peak value $n_{\mathrm{p}}$. In this process, due to the development of larger settlement above the water bag compared to that above the pile cap (Wang et al. 2018a), the soil arching effect is strengthened, with more dynamic stress transferred from the water-bag area to the pile-cap area. The corresponding loading cycle for the peak value $n_{p}$ is defined as the characteristic value $N_{\text {cha }}$. After the characteristic value, the dynamic stress concentration ratio presents a slightly decreasing trend with the increase of loading cycles at high WL, suggesting that the soil arching effect tends to be slightly weakened beyond the characteristic loading cycle $N_{\text {cha }}$. With the WL lowering or loading at unsaturated state (from $N=820000$ ), the $n$ values rarely change, due to the stable state of the soil arching, which is in good agreement with the observations from Fig. $5 b$ and the negligible variations of differential settlement (between the pile cap and the water bag) in these two procedures (Wang et al. 2018a). 
Fig. 6. Variations of dynamic stress concentration ratio with cycles. $h$, elevation. [Color online.]

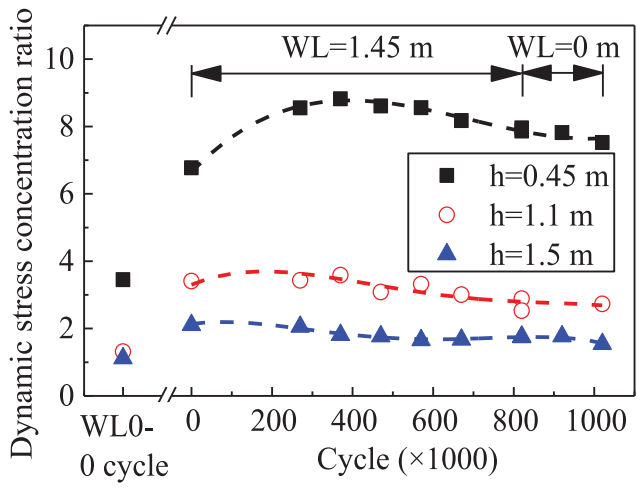

According to the limit equilibrium analysis conducted by Hewlett and Randolph (1988), the crown and foot of the soil arching are two critical zones existing in the pile-supported embankment. It is observed in Fig. 6 that at a given loading cycle, the sensor located at lower elevation shows higher values of dynamic stress concentration ratio. That is to say, at a given cycle, the arching effect is more developed near the foot of the soil arching or the top of the pile caps. In addition, the characteristic loading cycle for the dynamic stress concentration ratio to reach the peak point is different for the sensors at each elevation. The $N_{\text {cha }}$ value for $h=0.45 \mathrm{~m}$ (where $h$ is elevation) is around 350000 cycles, which is much higher than those at the elevations of $1.1 \mathrm{~m}\left(\mathrm{~N}_{\mathrm{cha}}=\right.$ 180000 cycles $)$ and $1.5 \mathrm{~m}$ ( $\mathrm{N}_{\text {cha }}=90000$ cycles $)$. In other words, the arching effect near the crown of the soil arching more easily reaches the peak state due to the load transmitting path. In summary, during cyclic loading at high WL, the stable state of soil arching was obtained earlier near the crown of the soil arching, while the arching effect was still more significant at the foot of the soil arching or on the top of the pile caps.

\section{Soil stress along geogrid}

To investigate the effect of the geogrid on the mechanism of load transmission, the variations of the quasi-static and dynamic soil stresses along the geogrid are plotted against loading cycles for different WLs and loading cycles, as shown in Fig. 7. The legend "PC" represents the area above the pile cap (sensors 4-2 and 5-2) and the legend "WB" indicates that the sensors are located above the water bag (sensors 4-1 and 5-1). In terms of quasi-static stress, the two sensors above the pile cap both present increasing trend of soil stress with the increase of $\mathrm{WL}$ (Fig. 7a). Then, the values continue to rise as the loading cycle increases till a relatively stable state is reached at about $N=470000$. However, the quasistatic stresses above the water bag both decrease slightly with the rising of WL and the values stay relatively stable during the cyclic loading process. By contrast, the dynamic stresses above the pile cap change as the WL or loading cycle increases, with much smaller variation range compared to that of the quasi-static stresses for corresponding sensors (Fig. 7b). For the dynamic stresses above the water bag, the values rarely change in comparison with those at the initial state.

In the GRPS track bed, the geogrid reinforcement is installed to transfer loads to the piles and thus to reduce the settlement (Jones et al. 2010; Chen et al. 2016b). From Fig. 7a, it can be observed that for the sensors above the pile cap, the quasi-static soil stress below the geogrid is larger than that above the geogrid at a given loading cycle, suggesting that part of the static load of the model from above is transferred onto the soil below the geogrid. By contrast, for the sensors above the water bag at a given cycle, the quasistatic soil stress presents slightly lower values below the geogrid, with a minor portion of loads from above being borne by the
Fig. 7. Variations of quasi-static and dynamic soil stress along geogrid. [Color online.]
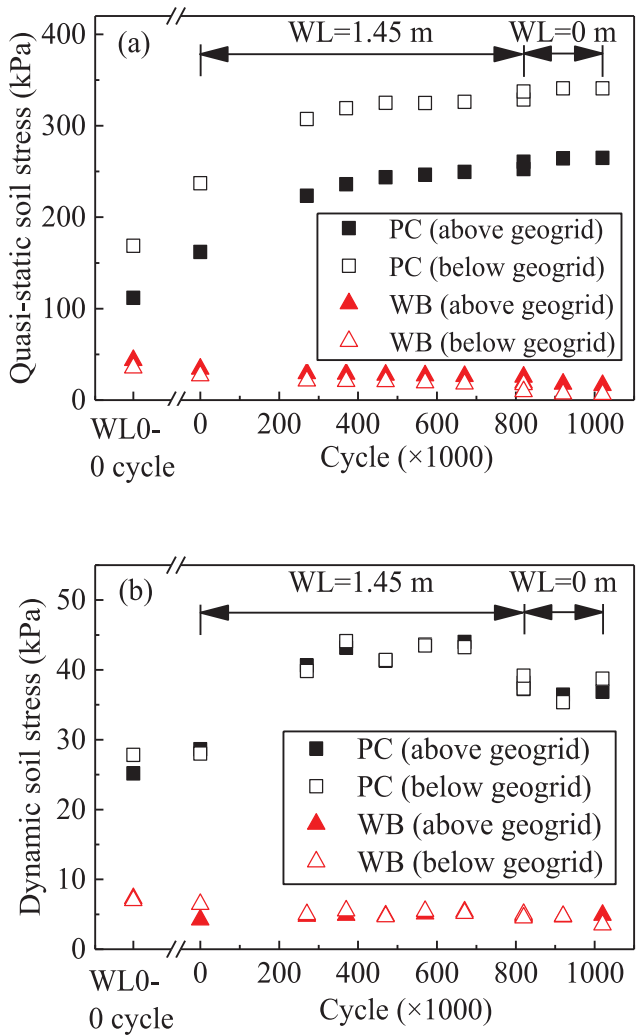

geogrid. Nevertheless, the effect of the geogrid on the transfer of dynamic soil stress is much less pronounced, showing approximately similar values for the sensors above and below the geogrid (Fig. 7b).

To quantitively evaluate the effect of the geogrid on the load transfer mechanism, a parameter namely stress difference along the geogrid $\Delta \sigma_{\mathrm{g}}$ is introduced:

$$
\Delta \sigma_{\mathrm{g}}=\sigma_{\mathrm{b}-\mathrm{g}}-\sigma_{\mathrm{a}-\mathrm{g}}
$$

where $\sigma_{\mathrm{b}-\mathrm{g}}$ is the soil stress below the geogrid for the pile cap or water bag; $\sigma_{\mathrm{a}-\mathrm{g}}$ is the soil stress above the geogrid for the pile cap or water bag.

Figure 8 shows the variations of the stress difference with varying WLs and loading cycles for both quasi-static and dynamic soil stresses. As van Eekelen et al. $(2012 a, 2012 b)$ reported, the pile-cap soil stress below the geogrid consists of two parts: the pile-cap stress above the geogrid and the stress transmitted through the geogrid onto the pile cap (denoted as pile-cap stress difference here). Reversely, the physical meaning of the water-bag soil stress below the geogrid is illustrated as the subtraction of the water-bag stress above the geogrid and the stress transferred away by the geogrid (denoted as the negative value of water-bag stress difference). As shown in Fig. 8, the quasi-static stress difference above the pile cap varies from 60 to $80 \mathrm{kPa}$, which is 6 to 8 times larger than the absolute value above the water bag (varying around $10 \mathrm{kPa}$ ). This phenomenon can be explained by the inverse triangular pattern of the tensile force distribution of the deflected geogrid above the water bag: the maximum and minimum vertical-directional tensile forces showing at the edge and in the center of the water bag, respectively (Chen et al. 2016b). As the sensors locate above the center of the water bag, where the minimum vertical-directional tensile force is developed, the load 
Fig. 8. Variations of quasi-static and dynamic stress difference along geogrid. [Color online.]

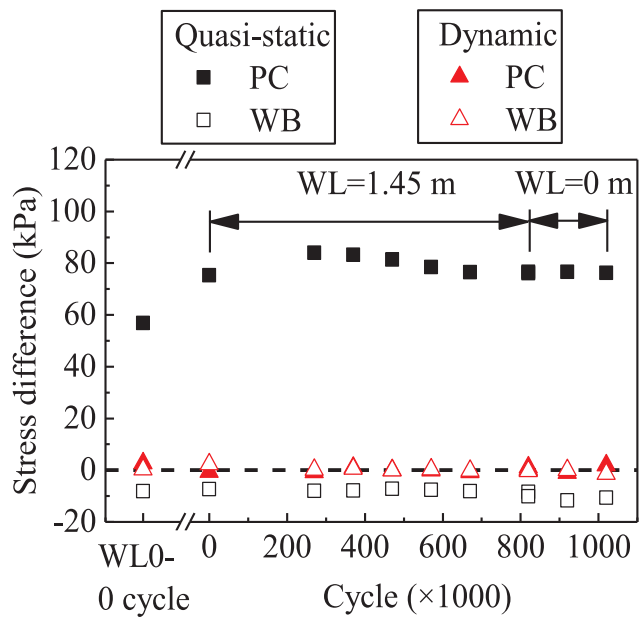

transfer is not significant. By contrast, the vertical-directional tensile force transferred towards the center of the pile cap presents higher values because of the deformation pattern of the geogrid and the friction between the geogrid and the soils. Thus, the quasi-static stress transferred through the geogrid onto the pile cap also presents higher values than the water-bag quasi-static stress transferred away by the geogrid (Fig. 8). However, this mechanism of load transfer by the geogrid cannot be identified for the dynamic stress as shown in Fig. 8: the dynamic stress differences are close to $0 \mathrm{kPa}$ for both the pile cap and the water bag. This is probably because at the relatively high frequency of the train moving load $(16 \mathrm{~Hz}$ for each axle at $360 \mathrm{~km} / \mathrm{h}$, see Wang et al. 2018a), the vicinity of the geogrid-reinforced soil vibrates as a whole. The transient variation of deformation of the geogrid is not significant, leading to a slight difference of dynamic stress for the soils above and below the geogrid.

\section{Soil stress on piled system (below geogrid)}

Figure 9 depicts the variations of dynamic soil stress at the I-I profile on the top of piled system shown in Fig. $1 b$ after typical processes (initial state, end of procedures 1, 2, 3, and 4). In this figure, the horizontal distance from track center " $0 \mathrm{~m}$ " represents the location of sensor 6-5 (Fig. 1b). It is observed that on the whole, the dynamic soil stresses on the pile cap at the center of the track bed present more distinct variations than those at other locations, suggesting that the WL and cyclic load transmitted to the bottom of the model influence the area right below the loading application site at the track center more significantly. At the end of procedure 1 (WL1.45-0 cycle), the dynamic stresses on the center pile cap showed a slight increasing trend compared to the initial state, whereas the $\sigma_{\mathrm{d}}$ values at other locations rarely changed (Fig. 9a). After 820000 loading cycles at high WL (WL1.45-820 000 cycles), the dynamic stresses on the center pile cap continued to increase, while the cyclic loading still hardly affected the $\sigma_{\mathrm{d}}$ values at other locations. After the WL lowering or loading at low WL, only the dynamic stress in the center area of the center pile cap showed a slight increasing trend (Fig. 9b)

It is also worth noting that for the center pile cap after each process, the dynamic stress at the edge of this pile cap presents a higher value than that at the center of the pile cap, which might be induced by the stress concentration (Halvordson et al. 2010; Jones et al. 2010). In consideration of the uneven stress distribution, a region with the size of $1.8 \mathrm{~m} \times 1.8 \mathrm{~m}$ (center-to-center pile cap spacing, shown by the dashed box in Fig. 1b) composed of the center pile cap and the surrounding water bags is selected to further study the mean dynamic soil stress. Based on the arrange-
Fig. 9. Variations of dynamic soil stress with horizontal distance from track center. [Color online.]
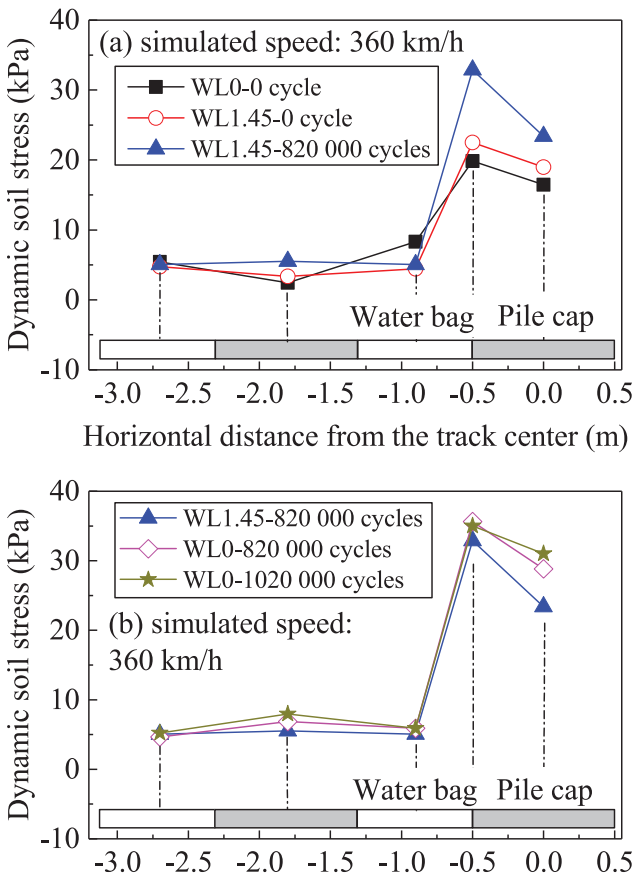

Horizontal distance from the track center $(\mathrm{m})$

ment of the sensors located in this region, the pile cap is divided equally into nine sections as shown in Fig. 10: one center section, four edge sections, and four corner sections. For the center section, edge section, and corner section, the dynamic soil stresses are denominated as $\sigma_{\mathrm{d}-\mathrm{PC}-\mathrm{cen}}, \sigma_{\mathrm{d}-\mathrm{PC}-\mathrm{ed}}$, and $\sigma_{\mathrm{d}-\mathrm{PC}-\mathrm{cor}}$, respectively. Because the diameter of the soil pressure sensor $(230 \mathrm{~mm})$ is slightly smaller than the area of the uniformly divided section (size: $333 \mathrm{~mm} \times 333 \mathrm{~mm}$ ), the measured data are used to represent the mean stress value on the divided section. In addition, the dynamic soil stresses on the corresponding edge and corner sections are considered to share the same value due to the symmetry of the model (Chen et al. 2016b). Therefore, the mean dynamic soil stress on the center pile cap $\sigma_{\mathrm{d}-\mathrm{PC}-\mathrm{mean}}$ can be approximately determined using the weighting method as

$$
\sigma_{\mathrm{d}-\mathrm{PC}-\text { mean }}=\frac{\sigma_{\mathrm{d}-\mathrm{PC}-\mathrm{cen}}+4 \sigma_{\mathrm{d}-\mathrm{PC}-\mathrm{ed}}+4 \sigma_{\mathrm{d}-\mathrm{PC}-\text {-or }}}{9}
$$

For the surrounding water bag region, it can be divided into eight sections according to the instrumentation shown in Fig. 10: two edge sections-1 (dynamic stress denominated as $\left.\sigma_{\mathrm{d}-\mathrm{WB}-\mathrm{ed} 1}\right)$, two edge sections-2 $\left(\sigma_{\mathrm{d}-\mathrm{WB}-\mathrm{ed} 2}\right)$, and four corner sections $\left(\sigma_{\mathrm{d}-\mathrm{WB}-\mathrm{cor}}\right)$. Due to the relatively large measuring area of the soil pressure sensor (230 mm diameter) and the symmetry of this model as illustrated above, the mean dynamic soil stress on this region $\sigma_{\text {d-wB-mean }}$ can also be estimated using the weighting method as

$$
\sigma_{\mathrm{d}-\mathrm{WB} \text {-mean }}=\frac{S_{1} \sigma_{\mathrm{d}-\mathrm{WB}-\mathrm{ed} 1}+S_{2} \sigma_{\mathrm{d}-\mathrm{WB}-\mathrm{ed} 2}+S_{3} \sigma_{\mathrm{d}-\mathrm{WB} \text {-cor }}}{S}
$$

where $S_{1}, S_{2}, S_{3}$, and $S$ represent the areas of two edge sections-1, two edge sections-2, four corner sections, and the whole water bag region, respectively. Finally, the dynamic stress concentration ratio in terms of mean stress can be obtained after the determinations of $\sigma_{\mathrm{d}-\mathrm{PC}-\mathrm{mean}}$ and $\sigma_{\mathrm{d}-\mathrm{WB} \text {-mean }}$ 
Fig. 10. Region division of center pile cap and surrounding water bags. [Color online.]

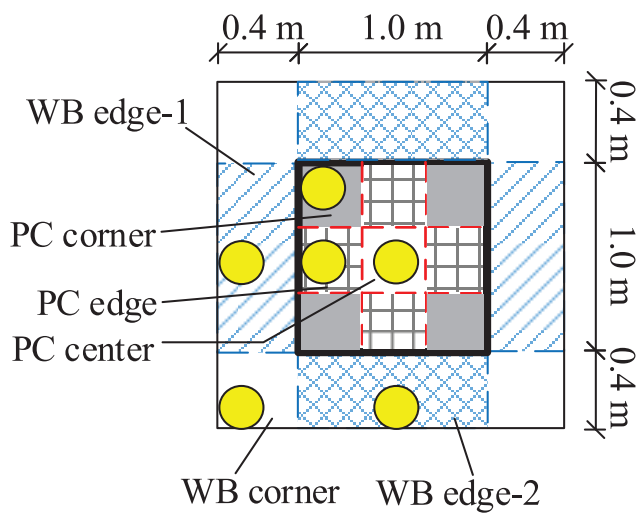

Figure 11 shows the variations of mean dynamic soil stresses and dynamic stress concentration ratio with varying WLs and loading cycles on the selected region as shown in Fig. 10. For the mean dynamic soil stress on the pile cap, the value increased slightly as the WL was raised. During the loading at high WL, the $\sigma_{\text {d-PC-mean }}$ value continued to increase with the loading cycle in the beginning and then tended to be stable at about $N=670000$. With the WL lowering, the $\sigma_{\text {d-PC-mean }}$ value showed a slightly decreasing behavior and it rose with a minor increment during the loading at low WL. Unlike the pile-cap dynamic stress, the mean dynamic soil stress on the water bag decreased with the WL increasing. Then, the mean dynamic stress kept at a relatively steady value around $6 \mathrm{kPa}$ in the following procedures. In general, the variations of the mean dynamic stress in this region were in agreement with the previous observations from Figs. 5 and 7.

With regard to the dynamic stress concentration ratio, the variation trend is similar to the observation from Fig. 6: an increasing trend followed by a relatively stable state. Interestingly, with lower elevation, the $N_{\text {cha }}$ value for the stable state of soil arching in this region is around 670000 cycles, which is much larger than those observed in Fig. 6 (ranging from 90000 to 350000 cycles). In addition, the concentration ratio presents larger values at a given process, compared to those at $h=1.1$ and $1.5 \mathrm{~m}$ from Fig. 6 . Thereby, these two observations provide a strong support to the previous interpretations about the evolution of soil arching: with lower elevation near the foot of the soil arching, the area may enter the stable state much later, while more significant soil arching effect may develop in this area.

\section{Conclusions}

Using the full-scale physical model of a GRPS railway track bed, the variations of soil stress were investigated at various WLs and loading cycles. Soil arching was developed and 1200000 loading cycles were applied on the unsaturated model to approach the in situ state before the present study. In this study, four testing procedures were applied: WL rising, loading at high WL, WL lowering, and loading at low WL. The obtained results allowed the effects of WL and loading cycle on the soil stress variations to be analyzed.

Below the height of soil arching, the distribution of dynamic soil stress with depth presented a distinct soil arching effect, with higher stress above the pile cap and lower stress above the water bag. Moreover, this effect became more significant with the WL rising and loading cycles increasing at high WL, until a peak dynamic stress concentration ratio was reached. Then, the soil arching tended to stay relatively stable as more loading cycles were applied. At deeper depth, the loading cycle for the soil arching to enter the stable state was larger and the soil arching effect was more developed. With the $\mathrm{WL}$ lowering and loading at low $\mathrm{WL}$,
Fig. 11. Variations of mean dynamic soil stress and dynamic stress concentration ratio with cycles. [Color online.]

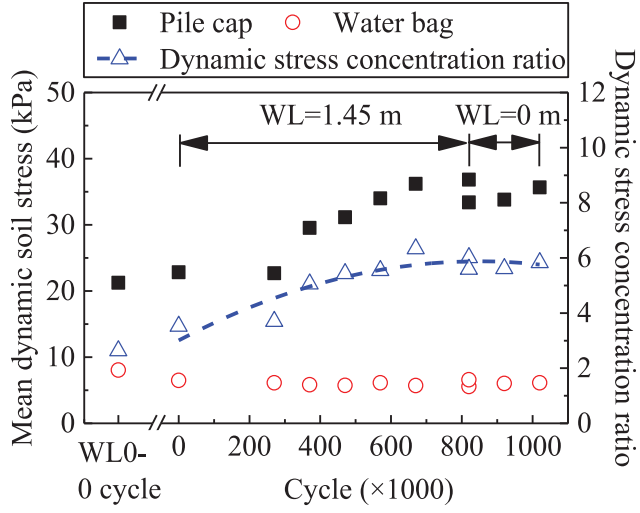

the dynamic stresses in the model change slightly because of the stable state of the soil arching.

Quasi-static stress was proved to be transferred from the water bag to the pile cap, through the geogrid. The quasi-static stress transmitted from the geogrid to the pile cap was much higher than that transmitted away from the water bag due to the reverse triangular distribution of vertical-directional tensile force and the stress transmission process along the geogrid. However, the dynamic stresses above either the pile cap or the water bag were rarely influenced by the geogrid, because of the slight variation of the transient deformation of the geogrid under cyclic loading with such high frequency.

For the top of the piled system, only the dynamic stress on the center pile cap changed with the varying WLs and loading cycles. The variations of the mean dynamic stress on the center pile cap region showed similar features to those in the regions located above. Nevertheless, at lower elevation, the dynamic stress concentration ratio needed more cycles to reach the peak value and the value at a given process appeared larger, which verified the aforementioned interpretations about the evolution of the soil arching.

\section{Acknowledgements}

Support from the General Program of National Natural Science Foundation of China (grant Nos. 41472244, 51608188) and the Provincial Key Research and Development Program of Hunan (grant No. 0105679005) is greatly acknowledged.

\section{References}

ASTM. 2011. Standard practice for classification of soils for engineering purposes (Unified Soil Classification System). ASTM standard D2487-11. ASTM International, West Conshohocken, Pa. doi:10.1520/D2487-11.

Bian, X.C., Jiang, H.G., Cheng, C., Chen, Y.M., Chen, R.P., and Jiang, J.Q. 2014. Full-scale model testing on a ballastless high-speed railway under simulated train moving loads. Soil Dynamics and Earthquake Engineering, 66: 368384. doi:10.1016/j.soildyn.2014.08.003.

Chen, R.P., Chen, J.M., and Wang, H.L. 2014. Recent research on the tracksubgrade of high-speed railways. Journal of Zhejiang University Science A, 15(12): 1034-1038. doi:10.1631/jzus.A1400342.

Chen, R.P., Jiang, P., Ye, X.W., and Bian, X.C. 2016a. Probabilistic analytical model for settlement risk assessment of high-speed railway subgrade. Journal of Performance of Constructed Facilities, 30(3): 04015047. doi:10.1061/(ASCE)CF. 1943-5509.0000789.

Chen, R.P., Wang, Y.W., Ye, X.W., Bian, X.C., and Dong, X.P. 2016b. Tensile force of geogrids embedded in pile-supported reinforced embankment: A full-scale experimental study. Geotextiles and Geomembranes, 44:157-169. doi:10.1016/ j.geotexmem.2015.08.001.

Chen, R.P., Wang, H.L., Hong, P.Y., Cui, Y.J., Qi, S., and Cheng, W. 2018. Effects of degree of compaction and fines content of the subgrade bottom layer on moisture migration in the substructure of high-speed railways. Proceedings of the Institution of Mechanical Engineers, Part F: Journal of Rail and Rapid Transit, 232(4): 1197-1210. doi:10.1177/0954409717710838.

Chen, Y.M., Cao, W.P., and Chen, R.P. 2008. An experimental investigation of soil arching within basal reinforced and unreinforced piled embankments. Geo- 
textiles and Geomembranes, 26(2): 164-174. doi:10.1016/j.geotexmem.2007. 05.004.

Chinanews. 2012. The railway embankment in Yuncheng, Shanxi suffers from water submerging problems and the transportation safety is threatened. http://www.chinanews.com/df/2012/07-16/4036437.shtml [16 July 2012]. [In Chinese.]

Gomes Correia, A., and Cunha, J. 2014. Analysis of nonlinear soil modelling in the subgrade and rail track responses under HST. Transportation Geotechnics, 1(4): 147-156. doi:10.1016/j.trgeo.2014.07.003.

Halvordson, K.A., Plaut, R.H., and Filz, G.M. 2010. Analysis of geosynthetic reinforcement in pile-supported embankments. Part II: 3D cable-net model. Geosynthetics International, 17(2): 68-76. doi:10.1680/gein.2010.17.2.68.

Han, G.X., Gong, Q.M., and Zhou, S.H. 2015. Soil arching in a piled embankment under dynamic load. International Journal of Geomechanics, 15(6): 04014094. doi:10.1061/(ASCE)GM.1943-5622.0000443.

Han, J., and Gabr, M.A. 2002. Numerical analysis of geosynthetic-reinforced and pile-supported earth platforms over soft soil. Journal of Geotechnical and Geoenvironmental Engineering, 128(1): 44-53. doi:10.1061/(ASCE)1090-0241(2002) 128:1(44).

Heitz, C., Lüking, J., and Kempfert, H.G. 2008. Geosynthetic reinforced and pile supported embankments under static and cyclic loading. In Proceedings of the 4th European Geosynthetics Conference, Edinburgh, UK, pp. 1-8.

Hewlett, W.J., and Randolph, M.F. 1988. Analysis of piled embankments. Ground Engineering, 21: 12-18.

Jenck, O., Combe, G., Emeriault, F., and De Pasquale, A. 2014. Arching effect in a granular soil subjected to monotonic or cyclic loading: kinematic analysis. In 8th International Conference on Physical Modelling in Geotechnics, Perth, Australia, pp. 1243-1249.

Jiang, H.G., Bian, X.C., Chen, Y.M., and Han, J. 2015. Impact of water level rise on the behaviors of railway track structure and substructure: full-scale experimental investigation. Transportation Research Record: Journal of the Transportation Research Board, 2476: 15-22. doi:10.3141/2476-03.

Jiang, H.G., Bian, X.C., Jiang, J.Q., and Chen, Y.M. 2016. Dynamic performance of high-speed railway formation with the rise of water table. Engineering Geology, 206: 18-32. doi:10.1016/j.enggeo.2016.03.002.

Jones, B.M., Plaut, R.H., and Filz, G.M. 2010. Analysis of geosynthetic reinforcement in pile-supported embankments. Part I: 3D plate model. Geosynthetics International, 17(2): 59-67. doi:10.1680/gein.2010.17.2.59.

Kang, X., Ge, L., Chang, K.-T., and Kwok, A.O. 2016. Strain-controlled cyclic simple shear tests on sand with radial strain measurements. Journal of Materials in Civil Engineering, 28(4): 0405169. doi:10.1061/(ASCE)MT.1943-5533.0001458.

Lindgren, J., Jonsson, D.K., and Carlsson-Kanyama, A. 2009. Climate adaptation of railways: lessons from Sweden. European Journal of Transport and Infrastructure Research, 9(2): 164-181.

Low, B.K., Tang, S.K., and Choa, V. 1994. Arching in piled embankments. Journal of Geotechnical Engineering, 120(11): 1917-1938. doi:10.1061/(ASCE)07339410(1994)120:11(1917).

Terzaghi, K. 1943. Theoretical soil mechanics. John Wiley \& Sons, New York, USA.

The Ministry of Railways of the People's Republic of China. 2009. Code for design of high speed railway. TB10621-2009. The Ministry of Railways of the People's Republic of China, Beijing, China. [In Chinese.]

Transportation Safety Board of Canada. 1998. Railway occurrence report R97D0113: Main-track derailment Canadian National Train No. E-283-21-05
Mile 34.55, Kingston Subdivision, Coteau-du-Lac, Quebec. Transportation Safety Board Press, Gatineau, Que., Canada.

van Eekelen, S.J.M., Bezuijen, A., Lodder, H.J., and van Tol, A.F. 2012a. Model experiments on piled embankments. Part I. Geotextiles and Geomembranes, 32: 69-81. doi:10.1016/j.geotexmem.2011.11.002.

van Eekelen, S.J.M., Bezuijen, A., Lodder, H.J., and van Tol, A.F. 2012b. Model experiments on piled embankments. Part II. Geotextiles and Geomembranes, 32: 82-94. doi:10.1016/j.geotexmem.2011.11.003.

van Eekelen, S.J.M., Bezuijen, A., and van Tol, A.F. 2013. An analytical model for arching in piled embankments. Geotextiles and Geomembranes, 39: 78-102. doi:10.1016/j.geotexmem.2013.07.005.

Wang, H.L., Chen, R.P., Luo, L., and Wu, J. 2015. Numerical modeling of moisture migration in high-speed railway subgrade. In International Symposium on Systematic Approaches to Environmental Sustainability in Transportation, Fairbanks, Alaska, USA, pp. 349-363.

Wang, H.L., Cui, Y.J., Lamas-Lopez, F., Dupla, J.C., Canou, J., Calon, N., Saussine, G., Aimedieu, P., and Chen, R.P. 2017. Effects of inclusion contents on resilient modulus and damping ratio of unsaturated track-bed materials. Canadian Geotechnical Journal, 54: 1672-1681. doi:10.1139/cgj-2016-0673.

Wang, H.L., Chen, R.P., Qi, S., Cheng, W., and Cui, Y.J. 2018a. Long-term performance of pile-supported ballastless track-bed at various water levels. Journal of Geotechnical and Geoenvironmental Engineering, 144(6): 04018035. doi: 10.1061/(ASCE)GT.1943-5606.0001890.

Wang, H.L., Cui, Y.J., Lamas-Lopez, F., Calon, N., Saussine, G., Dupla, J.C., Canou, J., Aimedieu, P., and Chen, R.P. 2018b. Investigation on the mechanical behavior of track-bed materials at various contents of coarse grains. Construction and Building Materials, 164: 228-237. doi:10.1016/j.conbuildmat. 2017.12.209.

Wang, H.L., Cui, Y.J., Lamas-Lopez, F., Dupla, J.C., Canou, J., Calon, N., Saussine, G., Aimedieu, P., and Chen, R.P. 2018c. Permanent deformation of track-bed materials at various inclusion contents under large number of loading cycles. Journal of Geotechnical and Geoenvironmental Engineering, 144(8): 04018044. doi:10. 1061/(ASCE)GT.1943-5606.0001911.

Wang, H.L., Chen, R.P., Liu, Q.W., Kang, X., and Wang, Y.W. 2019. Soil-geogrid interaction at various influencing factors by pullout tests with applications of FBG sensors. Journal of Materials in Civil Engineering, 31(1): 04018342. doi:10.1061/(ASCE)MT.1943-5533.0002537.

Zhao, L.S., Zhou, W.H., Fatahi, B., Li, X.B., and Yuen, K.V. 2016. A dual beam model for geosynthetic-reinforced granular fill on an elastic foundation. Applied Mathematical Modelling, 40: 9254-9268. doi:10.1016/j.apm.2016.06. 003.

Zhao, L.S., Zhou, W.H., and Yuen, K.V. 2017. A simplified axisymmetric model for column supported embankment systems. Computers and Geotechnics, 92: 96-107. doi:10.1016/j.compgeo.2017.07.027.

Zhou, W.H., Chen, R.P., Zhao, L.S., Xu, Z.Z., and Chen, Y.M. 2012. A semianalytical method for the analysis of pile-supported embankments. Journal of Zhejiang University-Science A (Applied Physics and Engineering), 13(11): 888-894. doi:10.1631/jzus.A12ISGT4.

Zhuang, Y., and Wang, K.Y. 2015. Three-dimensional behavior of biaxial geogrid in a piled embankment: numerical investigation. Canadian Geotechnical Journal, 52: 1629-1635. doi:10.1139/cgj-2014-0538.

Zhuang, Y., Wang, K.Y., and Liu, H.L. 2014. A simplified model to analyze the reinforced piled embankments. Geotextiles and Geomembranes, 42: 154165. doi:10.1016/j.geotexmem.2014.01.002. 